\title{
Cloud Point Extraction Used for Separation and Preconcentration of Trace Elements in Food Samples: A Review of Recent Applications
}

\author{
Ingrid Hagarová \\ Comenius University in Bratislava, Faculty of Natural Sciences, Institute of Laboratory Research on \\ Geomaterials, Mlynská dolina, Ilkovičova 6, 84215 Bratislava, Slovak Republic \\ E-mail: ingrid.hagarova@uniba.sk
}

Received: 2 September 2020; Accepted: 21 October 2020; Available online: 15 January 2021

\begin{abstract}
Food safety analysis involves many subfields. One of them is inorganic analysis aimed to the quantification of various trace elements. The main attention in this field is paid to toxic, potentially toxic, and essential trace elements. However in many cases, direct quantification of trace elements in a complex food matrix is almost impossible. To resolve this problem, a combination of a suitable separation procedure with a reliable quantification method is required to deliver accurate results. One of the separation techniques that is currently receiving considerable attention is cloud point extraction (CPE). The use of optimized CPE procedures with commonly available spectrometric methods (e.g., UV-Vis spectrophotometry, flame atomic absorption spectrometry, electrothermal atomic absorption spectrometry, hydride generation atomic absorption spectrometry, cold vapor atomic absorption spectrometry, inductively coupled plasma optical emission spectrometry) provides the powerful tool for reliable quantification of many trace elements (e.g., Al, As, Cd, Cu, Hg, Pb, Mn, Ni, Sb, Se, $\mathrm{Sn}, \mathrm{Zn}$, and many others) in various types of food matrices (e.g., fresh vegetables, ground grain samples, canned food samples, various powdered food samples, and many others), as documented by studies included in this review. Keywords: Cloud point extraction; Food samples; Trace elements; Spectrometric methods.
\end{abstract}

\section{Introduction}

The quality and safety of food products should be the primary concern of people working within the food processing industry. To ensure these requirements, reliable procedures for checking the food composition are required. Since food matrices are complex, heterogeneous mixtures of numerous and diverse biochemical substances, their analysis is a difficult task. For instance, food safety analysis involves many subfields, such as detection of pesticides and veterinary drug residuals, measurement of heavy metal ions, and assessment of banned food additives [1]. It means that development of reliable procedures for quantification of various organic as well as inorganic components is necessary. In the case of trace elements, the main attention is aimed to toxic and potentially toxic ones. It is due to the fact that many of them have cumulative properties and longstanding intake even trace concentrations can negatively affect human health [2]. On the other hand, the attention may be focused to the deficit of essential trace elements and their reliable quantification is also very important [3]. A special interest is paid to those essential trace elements which can become toxic after exceeding a certain concentration limit [4].

Spectrometric methods such as flame atomic absorption spectrometry (FAAS), electrothermal atomic absorption spectrometry (ETAAS), inductively coupled plasma optical emission spectrometry (ICP-OES), and inductively coupled plasma mass spectrometry (ICP-MS) are the most commonly used for the quantification of trace elements in various samples, including foodstuffs [5]. Elements that form volatile hydrides, such as As, Sb, $\mathrm{Bi}, \mathrm{Ge}, \mathrm{Pb}, \mathrm{Se}, \mathrm{Te}$ and $\mathrm{Sn}$, can be analyzed by hydride generation atomic absorption spectrometry (HG-AAS) [6]. Cold vapor atomic absorption spectrometry (CV-AAS) is usually used for the quantification of $\mathrm{Hg}$ [6]. The connection of hydride generation with inductively coupled plasma optical emission spectrometry (HG-ICP-OES) or mass spectrometry (HG-ICP-MS) is widely used to enhance the sensitivity of semimetal quantification and to eliminate the majority of matrix interferences [7]. Hydride generation atomic fluorescence spectrometry (HG-AFS) is also a suitable detection method for the quantification of hydride forming elements (mainly As, Se, and Sb), and cold vapor atomic fluorescence spectrometry (CV-AFS) can be successfully used for the quantification of $\mathrm{Hg}[8,9]$. In addition to the methods stated above, UV-Vis spectrophotometry can be also used for quantification of trace elements after their effective preconcentration using a suitable separation technique [10]. The suitability of a spectrometric method for the quantification of a target element is related to the problems to be examined. Analytical parameters such as quantification limit, precision and linear dynamic range play the most important role before making the decision [11]. 
However in many cases, direct quantification of (ultra)trace elements in a complex food matrix using above mentioned instruments is almost impossible. To resolve this problem, a combination of a suitable separation procedure with a reliable quantification method is required to deliver accurate results. Among separation techniques, extractions occupy an irreplaceable position in sample pretreatment procedures. Depending on the extraction phase being used, two main groups can be distinguished; liquid-liquid extraction (LLE) and solid phase extraction (SPE). Since their introduction, the both extraction techniques have undergone significant modifications. The main trend such as miniaturization of analytical systems results in new configurations and arrangements of these separation techniques. In addition to miniaturization, the effort to replace toxic organic solvents is another important step in development of new extraction modes. The use of surfactants instead of toxic organic solvents can be found in cloud point extraction (CPE) procedures. Therefore, CPE can be considered as a new alternative of LLE, which is consistent with principles of green analytical chemistry.

The aim of this paper is to show analytical potential of CPE procedures connected with commonly available spectrometric methods stated above for quantification of (ultra)trace elements in complex food matrices. Published papers describe low limits of detection, acceptable precision, and accurate results achieved for analysis of fresh vegetables (e.g., spinach, lettuce, cabbage, and many others), legumes (e.g., peas, lentils, and many others), ground grain samples (e.g., wheat flour, rice flour, corn flour), canned food samples (e.g., tomato paste, fish, okra, beans, peas, and many others), various powdered food samples (milk powder, chocolate powder, potato starch, maize starch), fruit juices (cherry, orange, peach, pear, apricot, apple, grape, and others), tea samples, and many others.

\section{Cloud point extraction}

Cloud point extraction (CPE) uses neutrally charged surfactants (nonionic or zwitterionic). An aqueous solution of such surfactants at a concentration higher than critical micellar concentration (CMC) becomes turbid and separates into two isotropic phases if an external condition is changed (e.g., temperature, pressure, $\mathrm{pH}$, or ionic strength). The surfactant solution becomes turbid because it attains the cloud point (i.e. incomplete solubilization) [12]. At this point, the original surfactant solution separates into a surfactant phase of a small volume, which is rich in surfactant and contains an analyte trapped by micellar structures (so-called surfactant-rich phase; SRP) and a bulk diluted aqueous phase (so-called surfactant-poor phase or equilibrium solution).

In element analysis, the CPE methodology can be briefly summarized as follows. In the first step, a complexing agent is usually added to a system to obtain the hydrophobic complex which remains in the hydrophobic core of the micelles in the SRP. This is followed by the addition of a surfactant and heating in a water bath to induce cloud point formation. In this moment, two isotropic phases are formed and their separation is accelerated by centrifugation. Afterwards, the system is usually cooled in an ice-bath in order to increase the viscosity of the SRP. The final step of CPE procedure is decantation of an aqueous phase. The highly viscous SRP is obtained and conventionally diluted by organic solvents (mainly methanol or ethanol) acidified by mineral acids (mainly $\mathrm{HNO}_{3}$ or $\mathrm{HCl}$ ). Such diluted sample is now ready for measurement. Schematic diagram showing the CPE procedure can be seen in Figure 1.



Figure 1. Schematic diagram of CPE procedure developed for separation and preconcentration of trace elements.

From the methodology stated above, it is evident that optimization of various experimental conditions needs to be done, including optimizing $\mathrm{pH}$ (which plays a crucial role in complex formation and subsequent extraction), concentration of a surfactant, concentration of a complexing agent, incubation temperature and time, and centrifugation time. In some cases, the addition of salts, alcohols, some other surfactants and some organic compounds may also be helpful (salting-out effect). The factors, such as $\mathrm{pH}$, surfactant concentration, complexing agent concentration, ionic strength, incubation temperature and time, have significant effects on the extraction 
recoveries achieved. The factors, such as time for centrifugation and time for ice bath, have less significant effects on the extraction recoveries achieved [13].

Selection of a suitable diluting agent for decreasing viscosity of the SRP is also important step. It is considerably dependent on the detection method used. In the case of AAS methods, no serious difficulties are described in the literature after using acidified organic solvents $[14,15]$. In the case of ICP methods, the main characteristics of plasma can be negatively influenced, and so, the SRP is usually diluted by concentrated mineral acids [13,14]. In the case of UV-Vis spectrophotometry, dilution with pure organic solvents (such as methanol, ethanol, acetone, acetonitrile, tetrahydrofuran, etc.) is usually done [16].

Surfactants and complexing agents are the key components in most CPE procedures. Nonionic surfactants (mainly polyoxyethylated alkylphenols, from the Triton and PONPE series) are the most widely employed for $\mathrm{CPE}$ in element analysis because of their commercial availability of high purity grade, relatively low price, stability, non-volatility, low toxicity and low flammability. Among them, Triton X-114 (polyoxyethylene-7.5-octylphenoxy ether) is preferably used due to its low cloud point temperature $\left(23-25^{\circ} \mathrm{C}\right.$; which is particularly important for the extraction of thermally unstable complexes) and high density of the SRP $(1.052 \mathrm{~g} / \mathrm{mL}$; which facilitates phase separation by centrifugation) [13,17]. Majority of the published CPE procedures are associated with the use of Triton X-114 (more than 80\%).

Various complexing agents are used in CPE procedures. Among them, pyridylazo and thiazolylazo derivatives have been widely employed due to their low solubility in water and ability to form hydrophobic complexes with a large number of elements [11,18,19]. Reagents, such as dithiocarbamates, dithizone and its derivatives, 8hydroxyquinoline and its derivatives, diethyldithiophosphate, or Schiff bases are the other groups of complexing agents frequently used in CPE procedures $[11,13,18]$.

\section{Sample preparation}

A great number of treatments are used to prepare foods for quantification of elements. Liquid food samples have an advantage over those associated with solid samples; they usually require less pretreatment steps, due to their liquid form. In some cases, very little sample preparation may be required. It can be simple sample dilution, evaporation, or distillation. Solid food samples are usually washed with deionized water, dried to constant weight, ground into fine powder, and sieved. After homogenization, an aliquot of the powdered sample is used for wet (acid) digestion or dry ashing [20]. In this case, the organic matter is removed or converted to simpler inorganic forms. Acid digestion can be done by using $\mathrm{HNO}_{3}$ [21-24], or a combination of $\mathrm{HNO}_{3}$ and $\mathrm{HClO}_{4}$ [25-29]. Often, a combination of $\mathrm{HNO}_{3}$ and $\mathrm{H}_{2} \mathrm{O}_{2}$ is applied [26,31-44]. Special combinations, such as $\mathrm{HNO}_{3} / \mathrm{HCl} / \mathrm{H}_{2} \mathrm{O}_{2}$ [45], or $\mathrm{H}_{2} \mathrm{SO}_{4} / \mathrm{H}_{2} \mathrm{O}_{2}$ and $\mathrm{HCl} / \mathrm{HClO}_{4}$ [46] can be also found in the published literature. Dry ashing at high temperatures (in the range of $500-600{ }^{\circ} \mathrm{C}$ ) can be used in the case of non-volatile elements. After that, the ash is usually moistened with a mixture of acids [35,40,47]. After achieving a clear solution, its dilution to a final desired volume by deionized water is made. Finally, an aliquot of such prepared solution is transferred to an extraction vessel and used for a CPE procedure.

Optimization of the CPE procedure for reliable separation of the target element can take some time. A number of researchers use the univariate strategy to find the optimal experimental conditions. This methodology is supposed to have easier interpretation but requires more experiments which increases the consumption of reagents, time, and energy. Multivariate optimization is faster, more economical and effective, due to the reduction of experiments. Several multivariate approaches such as the response surface methodology based on the central composite design [24], fractional factorial design [24,43], and Box-Behnken design [21,30,38,43] were exploited to identify interactions between the variables.

Optimization of the CPE procedure is always done on model solutions. After validation of the developed procedure by analyzing certified materials, the procedure is usually applied to water samples of various origin. Analysis of more complex matrices (such as geological, biological, or food samples) has been described more rarely. Examples of CPE procedures used for separation and preconcentration of trace elements in food samples will be discussed in the following paragraph.

\section{Examples of CPE procedures for separation and preconcentration of (ultra)trace elements in food samples}

Summarizing the works dedicated to the CPE procedures used for separation and preconcentration of (ultra)trace elements in food samples, these statements can be recorded.

In CPE procedures, nonionic surfactant Triton X-114 is the most often used. As it was mentioned above, it is due to its optimal physicochemical characteristics, such as low CPT (23-25 $\left.{ }^{\circ} \mathrm{C}\right)$ and high density of the SRP. Nevertheless, other surfactants than Triton X-114 can be also found in CPE procedures. Using Triton X-100 $[23,32,35]$, higher incubation temperatures have to be applied due to the fact that its CPT is around $65^{\circ} \mathrm{C}[13,17]$. 
Nonionic surfactant PONPE 7.5 has low CPT (in the range of $5-20{ }^{\circ} \mathrm{C}$, depending on its concentration used), but it can be found in CPE procedures more rarely [40]. Special nonionic surfactants such as Igepal CO-630 (nonylphenoxy poly(ethyleneoxy)ethanol, unbranched) [42] or copolymer L44 [(PEO) $\left.)_{10}(\mathrm{PPO})_{23}(\mathrm{PEO})_{10}\right]$ [38] were also used in CPE procedures for separation of trace elements from food samples. While all important characteristics of Igepal CO-630 were thoroughly described, for copolymer L44 just molar mass of $2200 \mathrm{~g} / \mathrm{mol}$ was stated.

In most CPE procedures, single surfactant solutions are applied. In the current literature, mixed surfactant solutions can be also found. The main reason is an effort to enhance measurement sensitivity. The cationic surfactant such as cetyltrimethylammonium bromide (CTAB) was used in combination with Triton X-114 [29,45] or Igepal CO-630 [42]. The cationic surfactant plays a dual role. It can serve both as a sensitivity enhancer as well as a counter ion. In these cases, lower limits of detection were achieved.

In conventional CPE procedures, clouding is usually initiated by heating the mixture consisting of sample, complexing agent and surfactant in a thermostated water bath. The other type of energy which can be used to accelerate the reactions and clouding phenomena is ultrasound. The heat generated by the high-frequency sound waves enhances intensity and rate of interactions between the surfactant and an aqueous phase. The rise in popularity of ultrasound in chemistry can be attributed to its ease of use, low cost and green nature. Ultrasonic process plays an important role in ultrasound-assisted CPE (UA-CPE), which was successfully applied also in analysis of food samples [24,29,40,42,43,45,46].

Extraction time usually takes around $40 \mathrm{~min}$. A novel arrangement of this extraction which is called rapidly synergistic CPE (RS-CPE) uses octanol as cloud point revulsant and synergic reagent. In this arrangement, extraction can be accomplished in $1 \mathrm{~min}$. In this case, CPT of the used surfactant is lowered and extraction can be done at room temperature without necessity of heating. The RS-CPE procedures were successfully applied for separation of trace $\mathrm{Ni}$ [28] and trace $\mathrm{Pb}$ [26] from various food samples. In the case of Pb, ligandless RS-CPE procedure was developed.

A new $\mathrm{pH}$-mediated ligandless extraction for trace $\mathrm{Pb}$ in a dual CPE (d-CPE) arrangement can be also found in the published literature [38]. In d-CPE, two extraction procedures follow each other. The first one is a conventional CPE procedure. In the second one, the SRP containing analytes is treated with aqueous solution followed by heating and centrifugation. The target analytes are back-extracted into the aqueous phase. Extraction time is doubled in comparison with conventional CPE, but selectivity of the method is significantly improved due to the removing of interfering species.

A combination of two CPE procedures was described for distinguishing V(IV) and V(V) in water and food samples [27]. This combination was based on the use of highly selective laboratory-made complexing agents. In the first CPE, V(IV) was retained in the SRP and aqueous phase was carefully collected and used for the second $\mathrm{CPE}$ in which extraction of $\mathrm{V}(\mathrm{V})$ was done.

A special method combining UA-CPE and dispersive $\mu$-solid phase extraction (D- $\mu$-SPE) was used for preconcentration of As, Cd, Cr, Co, Sb, Pb and Tl [24]. In this case, a nanocomposite (Mg/Al-LDH@CNTs) was used as an adsorbent for the analytes followed by its extraction into the SRP.

A brief summary of analytical methods where a CPE procedure was used for separation and preconcentration of trace elements in various food samples before their spectrometric quantification can be seen in Table 1.

\section{Concluding remarks}

In this paper, the use of greener extraction procedures for separation and preconcentration of (ultra)trace elements in food samples has been summarized. Cloud point extraction as a technique in which small amounts of surfactants are used instead of high-volumed toxic organic solvents follows the principles of green analytical chemistry. After optimization of all experimental conditions, the developed CPE procedures can offer high extraction efficiency, high preconcentration factors, low cost, and safety. High efficiency and high preconcentration factors are the most important parameters for (ultra)trace analysis of complex matrices. Complexity of foodstuff matrices and the strict limits established for various toxic substances make necessary the continuous improvement of the current sample pretreatment procedures for food analysis. In case of trace elements, the possibility to use commonly available spectrometric methods in connection with CPE procedures is a great benefit for any food safety laboratory which uses such instrumentation. After CPE preconcentration, limits of detection for all spectrometric methods used can be improved, in some cases, by several orders of magnitude. Connection of CPE procedures with spectrometric methods have demonstrated the high analytical potential for separation/preconcentration and quantification of many (ultra)trace elements (e.g., $\mathrm{Al}, \mathrm{As}, \mathrm{Cd}, \mathrm{Cu}, \mathrm{Hg}, \mathrm{Pb}, \mathrm{Mn}$, $\mathrm{Ni}, \mathrm{Sb}, \mathrm{Se}, \mathrm{Sn}, \mathrm{Zn}$, and many others) in various types of food samples (e.g., fresh vegetables, ground grain samples, canned food samples, various powdered food samples, and many others). It is well documented by examples reviewed in this paper. 
Table 1. A brief summary of analytical methods where a CPE procedure was used for separation and preconcentration of trace elements in various foodstuffs

\begin{tabular}{|c|c|c|c|c|c|}
\hline Food sample & Trace element & $\begin{array}{l}\text { Complexing } \\
\text { agent }\end{array}$ & $\begin{array}{l}\text { Detection } \\
\text { method }\end{array}$ & $\begin{array}{l}\text { Limit of } \\
\text { detection }\end{array}$ & Ref. \\
\hline $\begin{array}{l}\text { Tomato paste, white bread, spinach, } \\
\text { lettuce, cabbage }\end{array}$ & $\mathrm{Mn}$ & Quinalizarin & UV-Vis & $0.8 \mu \mathrm{g} / \mathrm{L}$ & {$[22]$} \\
\hline $\begin{array}{l}\text { Canned lychee, tomato paste, pickled } \\
\text { lettuce }\end{array}$ & $\mathrm{Zn}$ & EDTA & $\mathrm{UV}-\mathrm{Vis}$ & $0.3 \mu \mathrm{g} / \mathrm{L}$ & [23] \\
\hline Rice flour, wheat flour & $\mathrm{Cu}$ & Isoleucine & $\mathrm{UV}-\mathrm{Vis}$ & $5 \mu g / L$ & {$[32]$} \\
\hline $\begin{array}{l}\text { Fruit juices (cherry, orange, peach, } \\
\text { pear, apricot, apple, grape), ice tea }\end{array}$ & $\mathrm{Cd}$ & $\mathrm{VBB}^{+}+\mathrm{I}^{-}$ & UV-Vis & $0.34 \mu \mathrm{g} / \mathrm{L}$ & {$[36]$} \\
\hline $\begin{array}{l}\text { Fruit juices (orange, apple, grape), } \\
\text { tomato paste, onion, potato, rice, } \\
\text { spinach, lettuce, cabbage, apple }\end{array}$ & $\mathrm{Al}$ & ARS & UV-Vis & $1.0 \mu \mathrm{g} / \mathrm{L}$ & {$[44]$} \\
\hline Maize starch, rice flour, potato starch & $\mathrm{Cu} ; \mathrm{Ni}$ & BDAP & FAAS & $0.1 ; 0.4 \mu \mathrm{g} / \mathrm{g}$ & {$[21]$} \\
\hline $\begin{array}{l}\text { Tomato paste, hazelnut, white bread, } \\
\text { spinach, lettuce, cabbage }\end{array}$ & $\mathrm{Ni} ; \mathrm{Mn}$ & Magneson I & FAAS & $2.7 ; 2.9 \mu \mathrm{g} / \mathrm{L}$ & {$[25]$} \\
\hline Spinach, rice, black tea & $\mathrm{Pb}$ & None & FAAS & $1.6 \mu \mathrm{g} / \mathrm{L}$ & {$[26]$} \\
\hline Cabbage, black tea & $\mathrm{Ni}$ & Furildioxime & FAAS & $0.6 \mu \mathrm{g} / \mathrm{L}$ & [28] \\
\hline $\begin{array}{l}\text { Canned fish, black and green tea, } \\
\text { honey, tomato sauce }\end{array}$ & $\mathrm{Pb} ; \mathrm{Co} ; \mathrm{Cu}$ & 1-PTSC & FAAS & $\begin{array}{l}0.50 ; 0.10 ; 0.15 \\
\mu g / g\end{array}$ & [31] \\
\hline $\begin{array}{l}\text { Rice samples, milk powder, walnut } \\
\text { powder, laver, kelp, millet }\end{array}$ & $\mathrm{Cd}$ & $\mathrm{MG}+\mathrm{I}^{-}$ & FAAS & $0.9 \mu \mathrm{g} / \mathrm{L}$ & [33] \\
\hline $\begin{array}{l}\text { Canned fish, canned okra, canned } \\
\text { beans, canned peas }\end{array}$ & $\mathrm{Cu} ; \mathrm{Pb} ; \mathrm{Cd} ; \mathrm{Fe}$ & DPTA & FAAS & $\begin{array}{l}0.48 ; 1.33 ; 0.38 \\
1.85 \mu \mathrm{g} / \mathrm{L}\end{array}$ & [34] \\
\hline Millet samples & Co & MOSDAA & FAAS & $0.47 \mu \mathrm{g} / \mathrm{L}$ & [37] \\
\hline Fish, spinach & $\mathrm{Pb}$ & None & FAAS & $1.9 \mu \mathrm{g} / \mathrm{L}$ & [38] \\
\hline $\begin{array}{l}\text { Milk samples, cereals, whole meal } \\
\text { biscuit, mint, green beans, lentils, } \\
\text { carrots, cabbage, green tea, tomato }\end{array}$ & Mo; V & $\mathrm{NBH}^{+}$ & FAAS & $0.86 ; 1.65 \mu \mathrm{g} / \mathrm{L}$ & {$[40]$} \\
\hline $\begin{array}{l}\text { Juices (orange, apple, tomato), rice, } \\
\text { spinach, cabbage }\end{array}$ & $\begin{array}{l}\text { Fe; Co; Cu; } \\
\mathrm{Zn}\end{array}$ & ETB & FAAS & $\begin{array}{l}1.5 ; 0.23 ; 0.71 \\
0.35 \mu \mathrm{g} / \mathrm{L}\end{array}$ & {$[41]$} \\
\hline $\begin{array}{l}\text { Lettuce, spinach, mint, peas, etc. } \\
\text { Lentils, nuts, oats, rice, etc. }\end{array}$ & Zn; Ni; Co & Carmine & FAAS & $\begin{array}{l}0.5 ; 0.6 ; 0.6 \\
\mu g / \mathrm{kg}\end{array}$ & [42] \\
\hline Chocolate samples & $\mathrm{Co} ; \mathrm{Ni}$ & HNB & FAAS & $0.56 ; 0.78 \mu \mathrm{g} / \mathrm{L}$ & [45] \\
\hline Milk powder & $\mathrm{Cu}$ & DDTC & FAAS & $1.1 \mu \mathrm{g} / \mathrm{L}$ & [47] \\
\hline $\begin{array}{l}\text { Oats, powdered chocolate, corn flour, } \\
\text { wheat flour }\end{array}$ & $\mathrm{Cu} ; \mathrm{Zn}$ & PAN & $\begin{array}{l}\text { FS- } \\
\text { FAAS }\end{array}$ & $0.10 ; 0.15 \mu \mathrm{g} / \mathrm{L}$ & {$[30]$} \\
\hline $\begin{array}{l}\text { Wine samples, tea and tomato } \\
\text { samples }\end{array}$ & $\mathrm{V}$ & $\mathrm{TAC}+\mathrm{AA}$ & ETAAS & $0.05 \mu \mathrm{g} / \mathrm{L}$ & [35] \\
\hline $\begin{array}{l}\text { Carrot, beetroot, canned beans, } \\
\text { spinach }\end{array}$ & Sb; Sn; Tl & PAN & ICP-OES & 8; 7; 10 ng/L & [43] \\
\hline Seafood samples & $\mathrm{Hg}$ & $\mathrm{MG}+\mathrm{I}^{-}$ & ICP-OES & $56.3 \mathrm{ng} / \mathrm{L}$ & [48] \\
\hline Broiler chicken tissues & $\mathrm{Hg}$ & DDTP & CV-AAS & $0.117 \mu \mathrm{g} / \mathrm{kg}$ & [49] \\
\hline $\begin{array}{l}\text { Corn, rice, fresh tomato, mushroom, } \\
\text { green and black tea }\end{array}$ & As, Se & $\mathrm{TR}+\mathrm{TA}$ & HG-AAS & $1.1 ; 3.5 \mathrm{ng} / \mathrm{L}$ & {$[50]$} \\
\hline Corn and rice samples & As & DDTP & HG-AFS & $1.34 \mu \mathrm{g} / \mathrm{kg}$ & [51] \\
\hline
\end{tabular}




\section{References}

[1] Jiang HL, Li N, Cui L, Wang X, Zhao RS. Recent application of magnetic solid phase extraction for food safety analysis. TrAC Trends in Analytical Chemistry. 2019;120:115632.

[2] Prashanth L, Kattapagari KK, Chitturi RT, Baddam VR, Prasad LK. A review on role of essential trace elements in health and disease. Journal of Dr. NTR University of Health Sciences. 2015;4(2):75-85.

[3] Skalny AV, Rudakov IA. Bioelements in medicine. Mir, Moscow. 2004.

[4] Ivanenko NB, Ganeev AA, Solovyev ND, Moskvin LN. Determination of trace elements in biological fluids. Journal of Analytical Chemistry. 2011;66:784.

[5] Korn MDA, Morte ESD, dos Santos DCMB, Castro JT, Barbosa JTP, Teixeira AP, Fernandes AP, Welz B, dos Santos WPC, dos Santos EBGN, Korn M. Sample preparation for the determination of metals in food samples using spectroanalytical methods: A review. Applied Spectroscopy Reviews. 2008;43(2):67-92.

[6] Dědina J. Atomization of volatile compounds for atomic absorption and atomic fluorescence spectrometry: On the way towards the ideal atomizer. Spectrochimica Acta Part B: Atomic Spectroscopy. 2007;62(9):846872.

[7] Rončević S, Benutić A, Nemet I, Gabelica B. Tin content determination in canned fruits and vegetables by hydride generation inductively coupled plasma optical emission spectrometry. International Journal of Analytical Chemistry. 2012:376381.

[8] Sanchez-Rodas D, Corns WT, Chen B, Stockwell PB. Atomic fluorescence spectrometry: a suitable detection technique in speciation studies for arsenic, selenium, antimony and mercury. Journal of Analytical Atomic Spectrometry. 2010;25(7):933-946.

[9] Chen Y, Belzile N. High performance liquid chromatography coupled to atomic fluorescence spectrometry for the speciation of the hydride and chemical vapour-forming elements As, Se, Sb and Hg: A critical review. Analytica Chimica Acta. 2010;671(1-2):9-26.

[10] Balcerzak M. Sample digestion methods for the determination of traces of precious metals by spectrometric methods. Analytical Sciences. 2002;18(7):737-750.

[11] Hagarová I. Cloud point extraction utilizable for separation and preconcentration of (ultra)trace elements in biological fluids before their determination by spectrometric methods: A brief review. Chemical Papers. 2017;71(5):869-879.

[12] Bezerra MD, Arruda MAZ, Ferreira SLC. Cloud point extraction as a procedure of separation and preconcetration for metal determination using spectroanalytical techniques: A review. Applied Spectroscopy Reviews. 2005;40(4):269-299.

[13] Hagarová I. Coupling cloud point extraction to atomic spectrometric methods for separation, preconcentration and speciation of metals. Chemické Listy. 2009;103(9):712-720.

[14] Stalikas CD. Micelle-mediated extraction as a tool for separation and preconcentration in metal analysis. TrAC Trends in Analytical Chemistry. 2002;21(5):343-355.

[15] Hagarová I, Bujdoš M, Matúš P, Čanecká L. The use of two extraction procedures in combination with electrothermal AAS for speciation of inorganic antimony in natural waters. Chemické Listy. 2012;106(2):136-142.

[16] Łobiński R, Marczenko Z. Recent advances in ultraviolet-visible spectrophotometry. Critical Reviews in Analytical Chemistry. 1992;23(1-2):55-111.

[17] Quina FH, Hinze WL. Surfactant-mediated cloud point extractions: an environmentally benign alternative separation approach. Industrial \& Engineering Chemistry Research. 1999;38(11):4150-4168.

[18] Pytlakowska K, Kozik V, Dabioch M. Complex-forming organic ligands in cloud-point extraction of metal ions: A review. Talanta. 2013;110:220-228.

[19] Hagarová I. Utilization of supramolecular solvents in the extraction of metals. Chemické Listy. 2014;108(10):949-955.

[20] Capar SG, Mindak WR, Cheng J. Analysis of toxic elements. Analytical and Bioanalytical Chemistry. 2007;389(1):159-169.

[21] Lemos VA, Santos MS, David GT, Maciel MV, Bezerra MA. Development of a cloud-point extraction method for copper and nickel determination in food samples. Journal of Hazardous Materials. 2008;159(23):245-251.

[22] Gouda AA. Cloud point extraction, preconcentration and spectrophotometric determination of trace amount of manganese (II) in water and food samples. Spectrochimica Acta Part A: Molecular and Biomolecular Spectroscopy. 2014;131:138-144.

[23] Azizi NAM, Rahim NY, Raoov M, Asman S. Optimisation and evaluation of zinc in food samples by cloud point extraction and spectrophotometric detection. Scientific Research Journal. 2019;16(1):41-59. 
[24] Nyaba L, Nomngongo PN. Determination of trace metals in vegetables and water samples using dispersive ultrasound-assisted cloud point-dispersive $\mu$-solid phase extraction coupled with inductively coupled plasma optical emission spectrometry. Food Chemistry. 2020;322:126749.

[25] Arpa Şahin Ç, Efeçınar M, Şatıroğlu N. Combination of cloud point extraction and flame atomic absorption spectrometry for preconcentration and determination of nickel and manganese ions in water and food samples. Journal of Hazardous Materials. 2010;176(1-3):672-677.

[26] Rahnama R, Eram S, Jamali MR. Ligand-less rapidly synergistic cloud point extraction as an efficient method for the separation and preconcentration of trace amounts of lead from food and water samples. Journal of the Brazilian Chemical Society. 2014;25(4):658-664.

[27] Khammas ZAA, Ibrahim ZT, Al-adilee KJ. Two-steps cloud point extraction-spectrophotometric method for separation, pre-concentration and determination of $\mathrm{V}(\mathrm{IV})$ and $\mathrm{V}(\mathrm{V})$ ions in real samples using laboratorymade organic reagents. International Research Journal of Pure and Applied Chemistry. 2015;8(1):33-48.

[28] Rahnama R, Najafi M. The use of rapidly synergistic cloud point extraction for the separation and preconcentration of trace amounts of $\mathrm{Ni}$ (II) ions from food and water samples coupling with flame atomic absorption spectrometry determination. Environmental Monitoring and Assessment. 2016;188(3):150.

[29] Zengin HB. Use of new polymeric composites for preconcentration of trace $\mathrm{Ag}^{+}$ions from the selected mushroom/vegetables by ultrasound-assisted cloud-point extraction coupled to microvolume UV-Vis spectrophotometry. International Journal of Environmental Analytical Chemistry. 2019;11:1-25.

[30] Ferreira HS, Santos ACN, Portugal LA, Costa ACS, Miró M, Ferreira SLC. Pre-concentration procedure for determination of copper and zinc in food samples by sequential multi-element flame atomic absorption spectrometry. Talanta. 2008;77(1):73-76.

[31] Citak D, Tuzen M. A novel preconcentration procedure using cloud point extraction for determination of lead, cobalt and copper in water and food samples using flame atomic absorption spectrometry. Food and Chemical Toxicology. 2010;48(5):1399-1404.

[32] Liang P, Yang J. Cloud point extraction preconcentration and spectrophotometric determination of copper in food and water samples using amino acid as the complexing agent. Journal of Food Composition and Analysis. 2010;23(1):95-99.

[33] Xiang G, Wen S, Wu X, Jiang X, He L, Liu Y. Selective cloud point extraction for the determination of cadmium in food samples by flame atomic absorption spectrometry. Food Chemistry. 2012;132(1):532-536.

[34] Citak D, Tuzen M. Cloud point extraction of copper, lead, cadmium, and iron using 2,6-diamino-4-phenyl1,3,5-triazine and nonionic surfactant, and their flame atomic absorption spectrometric determination in water and canned food samples. Journal of AOAC International. 2012;95(4):1170-1175.

[35] Filik H, Aksu D. Determination of vanadium in food samples by cloud point extraction and graphite furnace atomic absorption spectroscopy. Food Analytical Methods. 2011;5(3):359-365.

[36] Gürkan R, Altunay N. Determination of trace cadmium in nonalcoholic beverages by coupling cloud point extraction with spectrophotometry. Polish Journal of Food and Nutrition Sciences. 2013;63(4):253-260.

[37] Wang S, Meng S, Guo Y. Cloud point extraction for the determination of trace amounts of cobalt in water and food samples by flame atomic absorption spectrometry. Journal of Spectroscopy. 2013:735702.

[38] Wang Y, Han J, Liu Y, Wang L, Ni L, Tang X. Recyclable non-ligand dual cloud point extraction method for determination of lead in food samples. Food Chemistry. 2016;190:1130-1136.

[39] Gouda AA, Summan AM, Amin AH. Development of cloud-point extraction method for preconcentration of trace quantities of cobalt and nickel in water and food samples. RSC Advances. 2016;6(96):94048-94057.

[40] Gürkan R, Korkmaz S, Altunay N. Preconcentration and determination of vanadium and molybdenum in milk, vegetables and foodstuffs by ultrasonic-thermostatic-assisted cloud point extraction coupled to flame atomic absorption spectrometry. Talanta. 2016;155:38-46.

[41] Mortada WI, Kenawy IMM, Abdel-Rhman MH, El-Gamal GG, Moalla SMN. A new thiourea derivative [2(3-ethylthioureido)benzoic acid] for cloud point extraction of some trace metals in water, biological and food samples. Journal of Trace Elements in Medicine and Biology. 2017;44:266-273.

[42] Altunay N, Elik A, Bulutlu C, Gürkan R. Application of simple, fast and eco-friendly ultrasound-assistedcloud point extraction for pre-concentration of zinc, nickel and cobalt from foods and vegetables prior to their flame atomic absorption spectrometric determinations. International Journal of Environmental Analytical Chemistry. 2018;98(7):655-675.

[43] Biata NR, Mashile GP, Ramontja J, Mketo N, Nomngongo PN. Application of ultrasound-assisted cloud point extraction for preconcentration of antimony, tin and thallium in food and water samples prior to ICP-OES determination. Journal of Food Composition and Analysis. 2018;76:14-21.

[44] El Sheikh R, Atwa M, Gouda A, Abdullah A. Application of cloud point extraction for preconcentration, separation and determination of aluminum in food samples. Main Group Chemistry. 2019;18(4):345-356. 
[45] Temel NK, Sertakan K, Gürkan R. Preconcentration and determination of trace nickel and cobalt in milkbased samples by ultrasound-assisted cloud point extraction coupled with flame atomic absorption spectrometry. Biological Trace Element Research. 2018;186:597-607.

[46] Temel NK, Kuş B, Gürkan R. A new ion-pair ultrasound assisted-cloud point extraction approach for determination of trace $\mathrm{V}(\mathrm{V})$ and $\mathrm{V}(\mathrm{IV})$ in edible vegetal oils and vinegar by spectrophotometry. Microchemical Journal. 2019;150:104139

[47] Xiang G, Wen S, Jiang X, Liu X, He L. Determination of trace copper(II) in food samples by flame atomic absorption spectrometry after cloud point extraction. Iranian Journal of Chemistry and Chemical Engineering. 2011;30(3):101-107.

[48] Li YJ, Hu B. Sequential cloud point extraction for the speciation of mercury in seafood by inductively coupled plasma optical emission spectrometry. Spectrochimica Acta Part B: Atomic Spectroscopy. 2007;62(10):11531160.

[49] Shah AQ, Kazi TG, Baig JA, Afridi HI, Kandhro GA, Arain MB, Kolachi NF, Wadhwa SK. Total mercury determination in different tissues of broiler chicken by using cloud point extraction and cold vapor atomic absorption spectrometry. Food and Chemical Toxicology. 2010;48(1):65-69.

[50] Altunay N, Gürkan R. Determination of sub-ng g(-1) levels of total inorganic arsenic and selenium in foods by hydride-generation atomic absorption spectrometry after pre-concentration. Food Additives and Contaminants Part A: Chemistry Analysis Control Exposure \& Risk Assessment. 2017;34(3):390-403.

[51] Castor JMR, Portugal L, Ferrer L, Hinojosa-Reyes L, Guzmán-Mar JL, Hernández-Ramírez A, Cerdà V. An evaluation of the bioaccessibility of arsenic in corn and rice samples based on cloud point extraction and hydride generation coupled to atomic fluorescence spectrometry. Food Chemistry. 2016;204:475-482.

(C) 2021 by the author(s). This work is licensed under a Creative Commons Attribution 4.0 International License (http://creativecommons.org/licenses/by/4.0/). Authors retain copyright of their work, with first publication rights granted to Tech Reviews Ltd. 